\title{
Comportamento do estresse oxidativo e da capacidade antioxidante total em ratos submetidos a retalhos cutâneos isquêmicos ${ }^{1}$
}

\author{
Moacir Cymrot $^{2}$, Sandro Percário ${ }^{3}$, Lydia Masako Ferreira $^{4}$
}

\begin{abstract}
Cymrot M, Percário S, Ferreira LM. Comportamento do estresse oxidativo e da capacidade antioxidante total em ratos submetidos a retalhos cutâneos isquêmicos. Acta Cir Bras [serial online] 2004 Jan-Fev;19(1). Disponível em URL: http://www.scielo.br/acb.

RESUMO - Objetivo: Estudar o comportamento do estresse oxidativo (MDA) e da defesa antioxidante (CAT), em fragmentos de retalhos cutâneos randômicos isquêmicos em ratos. Métodos: Foram utilizados 18 ratos adultos jovens, machos (Wistar EPM-1, 290 a 350g), submetidos à elevação de retalho cutâneo de base cranial no dorso, divididos em três grupos $(\mathrm{N}=6)$ em função do tempo pós-operatório: imediato (POI), terceiro e sétimo dias (PO3 e PO7, respectivamente). Ao final, foram coletadas amostras de sangue periférico e fragmentos de tecido do retalho e de área cutânea normal fora do retalho para dosagem de MDA e de CAT. Resultados: Para MDA no soro, o grupo POI apresentou valores significativamente menores que os grupos PO3 e PO7, os quais não diferiram entre si. Não foi encontrada diferença entre os valores das amostras cutâneas em nenhum dos três grupos estudados. Para os valores da capacidade antioxidante total (CAT) não houve diferença significante entre os três grupos, quando analisado o soro dos animais, no entanto, para as amostras de fragmentos cutâneos, os valores diminuíram significativamente em função do tempo. Conclusão: A inexistência de diferença para os valores de MDA nas amostras cutâneas entre os grupos e a diminuição dos valores da CAT ao longo do tempo sugere que a presença de necrose na porção distal dos retalhos dos animais do grupo PO7 decorra, não somente da agressão oxidativa, mas também da diminuição da capacidade de defesa antioxidante local.
\end{abstract}

DESCRITORES - Retalhos cirúrgicos. Radicais livres. Antioxidantes. Ratos.

\section{Introdução}

A utilização de retalhos cutâneos é ainda um recurso muito freqüente em Cirurgia Plástica, sendo a necrose a complicação mais temida.

A elevação do retalho concorre para um período variável e transitório de comprometimento circulatório, que pode culminar com necrose da área isquêmica ${ }^{1}$. Adicionalmente, a isquemia prolongada leva à morte tecidual ${ }^{2}$.

Parte do dano tecidual, no retalho cutâneo randômico, se deve a reperfusão pós-isquêmica, quando o oxigênio retorna aos tecidos, com níveis críticos de energia, favorecendo a produção de radicais livres do oxigênio ${ }^{3,4}$.
Simultaneamente, há ativação de mecanismos antioxidantes naturais. Se o produto desta reação tender para o excedente de radicais livres, ocorrerão fenômenos oxidativos, auto-alimentáveis, chamados de estresse oxidativo, destacando-se a peroxidação lipídica, que culminarão com a lesão da membrana celular ${ }^{5,6}$.

Adamson e col. ${ }^{7}$ relacionaram em 1967, pela primeira vez, a diminuição do sofrimento de retalhos cutâneos com o uso de inibidores de radicais livres.

Recentemente, a participação das defesas antioxidantes nestes mecanismos oxidativos tem sido mais investigada, no entanto, efetivamente pouco se sabe sobre os mecanismos destas defesas em retalhos cutâneos.

O objetivo deste trabalho foi avaliar o estresse oxidativo, a capacidade antioxidante total e a correlação de ambos, assim como seus efeitos sobre a viabilidade de retalhos cutâneos isquêmicos no dorso de ratos e a repercussão sistêmica desta agressão, no período pós-operatório imediato, nos terceiro e sétimo dias após a elevação dos retalhos.

\section{Métodos}

Foram utilizados 18 ratos adultos jovens, machos, (Rattus novergicus: var. albinus, Rodentia, Mammalia), com peso variando de 290 a $350 \mathrm{~g}$, da linhagem Wistar EPM-1,

1. Trabalho realizado nos laboratórios de pesquisa das Disciplinas de Cirurgia Plástica e de Cirurgia Vascular do Departamento de Cirurgia da Universidade Federal de São Paulo - UNIFESP.

2. Doutor em Cirurgia Plástica pela UNIFESP.

3. Professor Titular da Universidade de Sorocaba e vice-líder do grupo de pesquisas em isquemia da Disciplina de Cirurgia Vascular do Departamento de Cirurgia da UNIFESP.

4. Professora Livre Docente, Titular e Chefe da Disciplina de Cirurgia Plástica do Departamento de Cirurgia da UNIFESP.

18 - Acta Cirúrgica Brasileira - Vol 19(1) 2004 
provenientes do Biotério Central da Universidade Federal de São Paulo - Escola Paulista de Medicina. Os animais foram mantidos em gaiolas individuais, sob as mesmas condições de temperatura, umidade e ruído, recebendo ração comercial $(\mathrm{Pu}-$ rina; Labina) e água ad libitum, durante todo o período de experimentação científica.

\section{Grupos de estudo}

Os ratos foram distribuidos, ao acaso, em três grupos:

Grupo PÓS-OPERATÓRIO IMEDIATO $(P O I)$ : seis animais, dos quais foram coletadas amostras (fragmentos cutâneos e soro) para avaliação laboratorial, imediatamente após a elevação de um retalho cutâneo isquêmico dorsal. Constituíram o grupo sham.

Grupo TERCEIRODIA PÓS-OPERATÓRIO (PO3): seis animais dos quais as amostras foram coletadas no terceiro dia após a elevação de um retalho semelhante ao do

grupo sham. Analisou-se, também neste dia, macroscopicamente, a extensão do tecido considerado normal deste retalho.

Grupo SÉTIMO DIA PÓS-OPERATÓRIO (PO7): seis animais dos quais as amostras foram coletadas no sétimo dia após a elevação de um retalho semelhante. Analisou-se, também neste dia, macroscopicamente, a extensão do tecido considerado normal deste retalho.

\section{Pré-operatório}

Para a realização do procedimento cirúrgico, os animais foram pesados e anestesiados (pentobarbital sódico, $40 \mathrm{mg} / \mathrm{kg}$ ), por via intraperitoneal, em uma só aplicação. Seguiu-se à realização de tricotomia digital no dorso do animal e a demarcação da área do retalho adequada a cada rato (proporcional ao seu peso), sendo convencionadas para um rato de $300 \mathrm{~g}$ as medidas de $10 \mathrm{~cm}$ para o comprimento e $4 \mathrm{~cm}$ para a largura, conforme as regras de três:

$$
\begin{aligned}
& 300 \mathrm{~g}-10 \mathrm{~cm} \\
& \text { peso do rato- X, } \\
& 300 \mathrm{~g}-4 \mathrm{~cm} \\
& \text { peso do rato }-\mathrm{Y},
\end{aligned}
$$

\section{Intra-operatório}

Após anestesia e demarcação cutânea, procedeu-se à elevação do retalho dorsal de base $\mathrm{cranial}^{8}$, constituído por epiderme, derme, panículo adiposo, panículo carnoso (musculatura estriada intrínseca) e uma fina camada de tecido subcutâneo ${ }^{2}$ (Figura

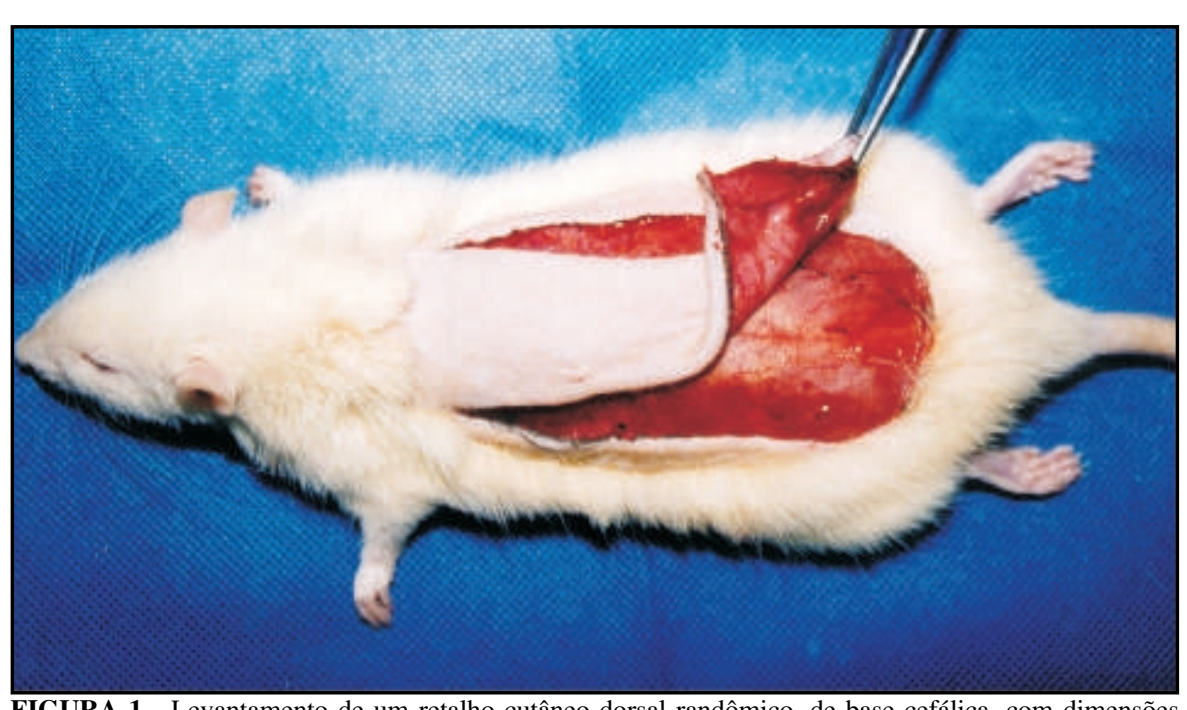

FIGURA 1 - Levantamento de um retalho cutâneo dorsal randômico, de base cefálica, com dimensões ao redor de $10 \times 4 \mathrm{~cm}$ (proporcional ao peso de cada animal).

\section{Pós-operatório}

\section{Grupo POI}

O retalho foi demarcado e dividido em 10 secções transversais e iguais, desde sua base cefálica até sua extremidade caudal (figura 4). Fragmentos alternados, iniciando-se pela extremidade distal (caudal), foram separados para o estudo. Após limpeza de coágulos, foram acondicionados em frascos individuais com $\mathrm{KCl}$ $1.15 \%$, identificados, numerados (1 a 5) e mantidos congelados em temperatura de $20 \mathrm{C}^{\circ}$ até a homogeneização, para posterior avaliação de malondialdeido (MDA) e da capacidade antioxidante total (CAT), dentro de um período de um mês. Da mesma forma foi tratado um fragmento cutâneo de área fora do retalho, de $1.5 \mathrm{~cm}^{2}$ (Figura 4), identificado como fragmento número 6 . Foi feita a coleta de sangue por exangüinação através da secção transversal dos grandes vasos cervicais e colocação do corpo do animal sobre um funil. Este material, após centrifugação, permaneceu estocado em temperatura de $-20 \mathrm{C}^{\circ}$ para posterior dosagem sérica de MDA e CAT, dentro de 24 horas.

\section{Grupos PO3 e PO7}

No terceiro e no sétimo dia pós-operatórios, após prévia anestesia, os animais do grupo PO3 e PO7, respectivamente, tiveram seus retalhos avaliados macroscopicamente. A área cutânea normal (coloração semelhante à de áreas não operadas) e a área total do retalho foram desenhadas por transparência, em papel vegetal, para sua medida pelo método descrito por Sasaki e Pang ${ }^{10}$. Seguiram-se os procedimentos de coleta de amostras, para dosagem do MDA e da CAT, semelhantes às descritas para o grupo POI.

O MDA e a CAT foram avaliados em amostras de soro e em homogeneizados de fragmentos cutâneos (Figura 4, posições 1 a 5), obtidos no retalho e em área fora deste (Figura 4, posição 6).

\section{Método estatístico ${ }^{11}$}

\section{Peso}

Para comparar os pesos dos animais nos diferentes grupos foi usada uma análise de variância a um fator (tempo) com três níveis, a saber, POI, PO3 e PO7. 


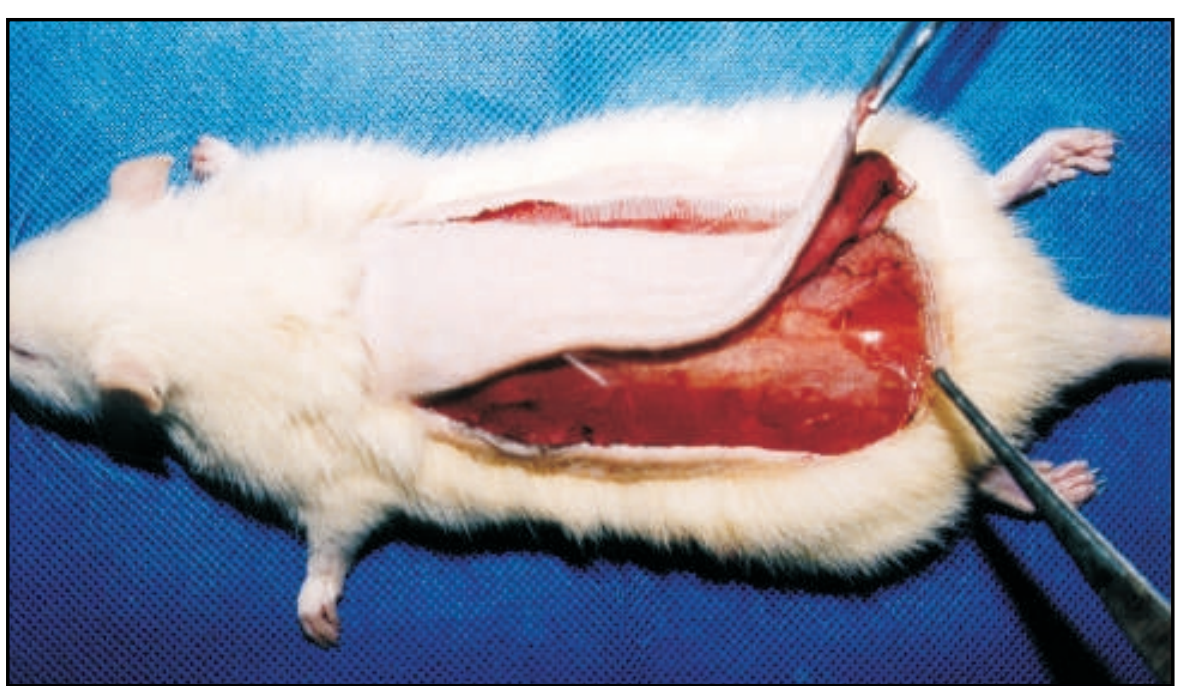

FIGURA 2 - Colocação de barreira plástica incolor entre o retalho cutâneo e seu leito.

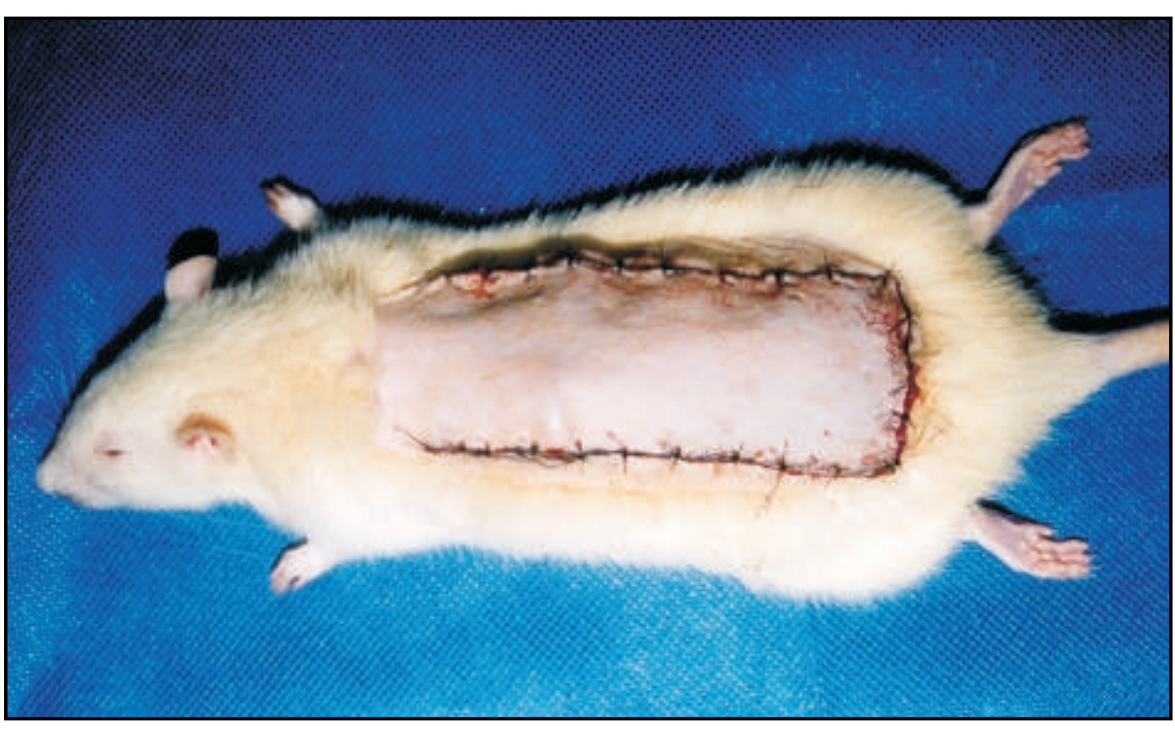

FIGURA 3 - Retalho suturado sobre seu leito original.

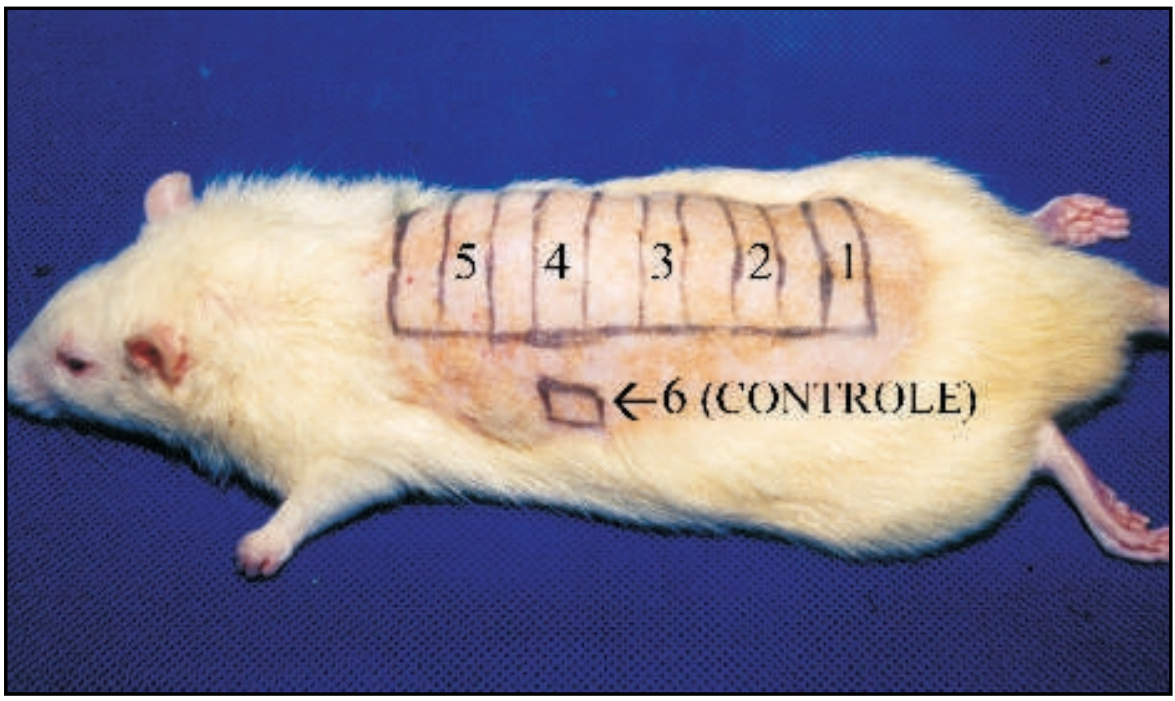

FIGURA 4 - Retalho cutâneo dorsal de base proximal, dividido em dez fragmentos transversais, desde sua base até sua extremidade distal e fragmento cutâneo desenhado fora do retalho, de $1,5 \mathrm{~cm}^{2}$

\section{Porcentagem de área cutânea normal no retalho $(\mathrm{PACN})$}

Para comparar a PACN de cada retalho foi usado o teste de comparação de duas médias nos tempos $\mathrm{PO} 3$ e PO7, com dados não pareados.

Para todas as variáveis, realizou-se uma análise descritiva dos dados onde foram calculadas a média amostral e o erro padrão da média (E.P.). Temos:

$$
\text { E.P. }=\frac{s}{\sqrt{n}}, \begin{aligned}
& \text { onde s é o desvio padrão } \\
& \text { amostral e no tamanho da } \\
& \text { amostra. }
\end{aligned}
$$

\section{MDA no soro}

Para comparar o MDA no soro nos diferentes grupos, foi usada uma análise de variância a um fator (tempo) com três níveis: POI, PO3 e PO7 e comparações múltiplas com o método de Tukey.

\section{MDA nos fragmentos}

Para analisar o MDA nos fragmentos foi utilizada uma análise de variância e covariância 3 x 6 balanceada com medidas repetidas no fator posição e $o$ animal hierárquico no fator tempo.

O fator tempo possui três níveis: POI, PO3 e PO7 e o fator posição possui seis níveis: posição 1 a 5 e controle.

Para esta análise foi utilizado o programa BMDP2V (versão 1.1, Los Angeles, Califórnia).

Também foram feitas comparações múltiplas utilizando o método de Tukey.

\section{CAT no soro}

Para comparar a CAT no soro nos diferentes grupos foi usada uma análise de variância a um fator (tempo) com três níveis, a saber, POI, PO3 e PO7.

\section{CAT nos fragmentos}

Para analisar a CAT nos fragmentos foi utilizada uma análise de variância e covariância 2 x 6 balanceada com medidas repetidas no fator posição e o animal hierárquico no fator tempo.

Para esta análise foi utilizado o programa BMDP2V (versão 1.1, Los Angeles, Califórnia). 


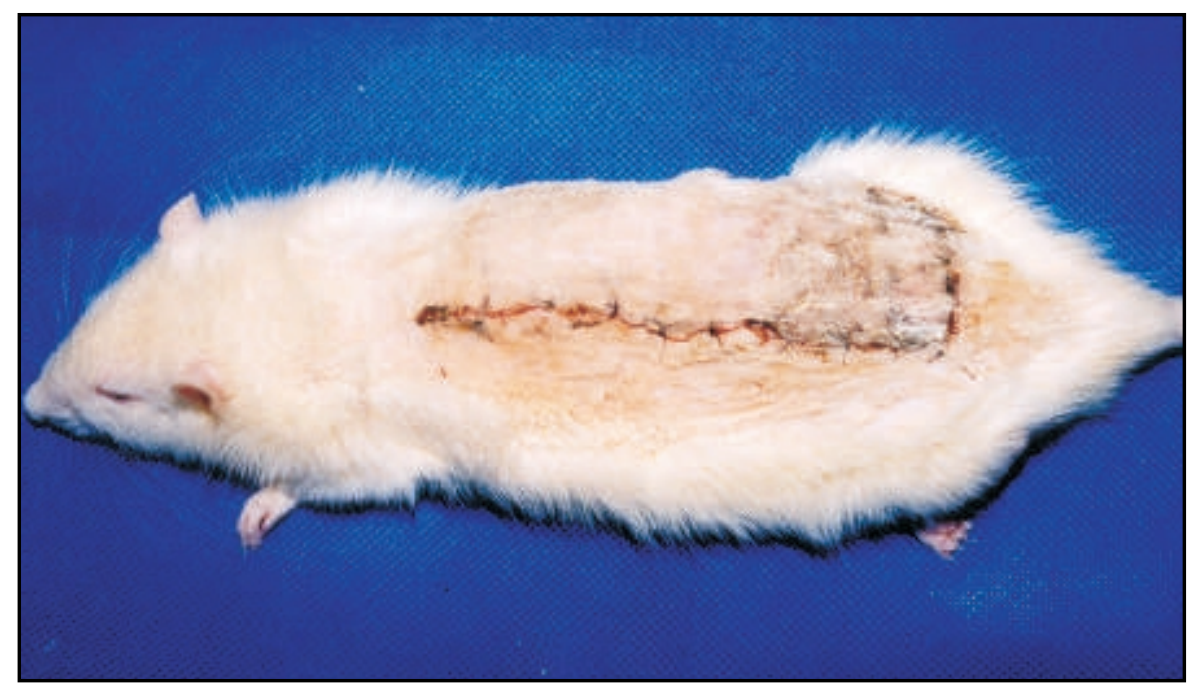

FIGURA 5 - Animal do grupo PO3 com limites imprecisos entre a área cutânea normal e a área com sofrimento cutâneo.

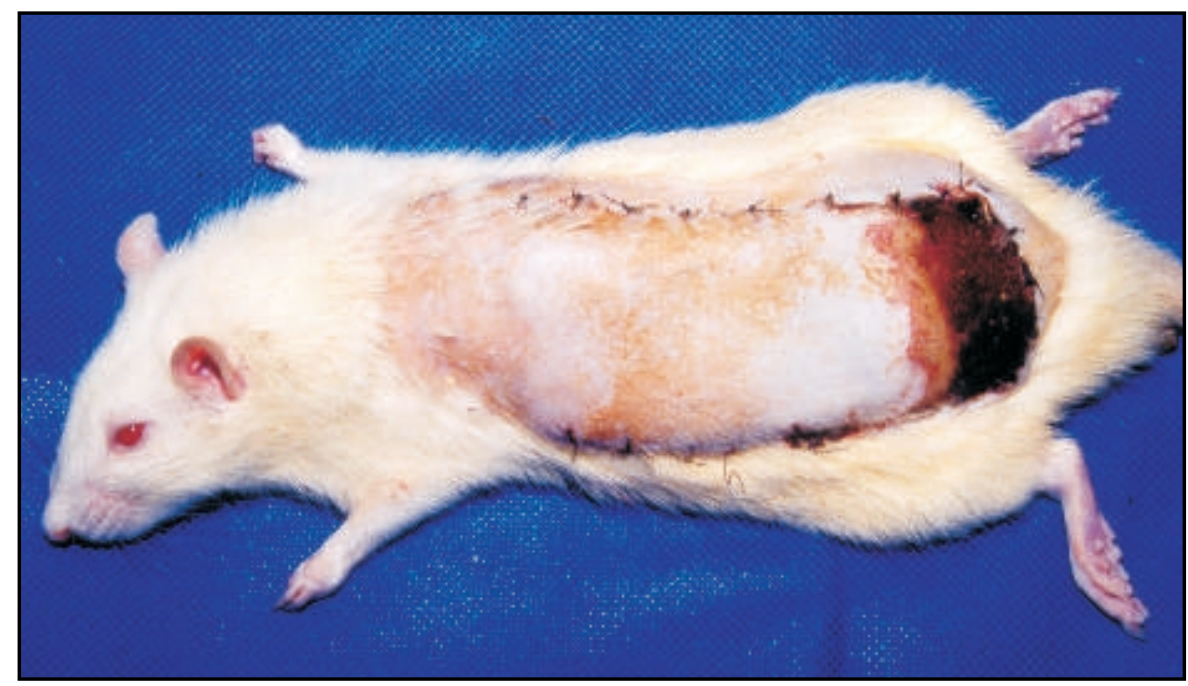

FIGURA 6 - Área cutânea com necrose mais bem delimitada, ao lado de área de sofrimento cutâneo, em animal do grupo PO7.

Também foi feita uma análise de regressão nos tempos POI, PO3 e PO7.

\section{MDA e CAT}

Foi feita uma análise das correlações entre o MDA e a CAT em cada fragmento eqüidistante da base em cada grupo e no soro de cada grupo.

\section{$M D A, C A T$ e PACN}

Foi feita uma análise das correlações entre PACN e as médias dos valores de MDAe CAT nos retalhos.

\section{Resultados}

Houve diferença estatisticamente significante entre a média da PACN nos grupos POI, PO3 e PO7 (Figura 7).
A média do MDA no soro do grupo POI mostrou-se significativamente menor do que nos grupos PO3 e PO7, que são estatisticamente iguais (Figura 8).

O valor do MDA nos fragmentos cutâneos não diferiu significativamente entre si, independentemente de sua posição e do grupo estudado (Figura 9).

Não houve diferença significativa entre os valores da CAT do soro nos três grupos (Figura 10).

Os valores da CAT nos fragmentos cutâneos do grupo PO3 foram significativamente menores do que os do grupo POI. Os valores do grupo $\mathrm{PO} 7$ foram significativamente menores do que os do grupo PO3 (Figura 11).
Foi observada uma relação linear entre os valores médios da CAT nos fragmentos cutâneos dos animais dos três grupos, em função do tempo, cuja reta de regressão é: CAT = 7,05 - 0,96 x tempo (Figura 12).

Não foi observada a relação linear entre os valores de MDA e CAT do soro dos animais (Tabela 1).

Não foi observada a relação linear entre os valores de MDA e CAT nos fragmentos cutâneos dos animais (Tabela 2).

Não foi observada a relação linear entre os valores da PACN e do MDA nos retalhos cutâneos nos grupos PO3 e PO7 (Tabela 3).

Não foi observada a relação linear entre os valores da PACN e da CAT nos retalhos cutâneos no grupo PO3 (Tabela 4). 
Cymrot $\mathrm{M}$ e col.

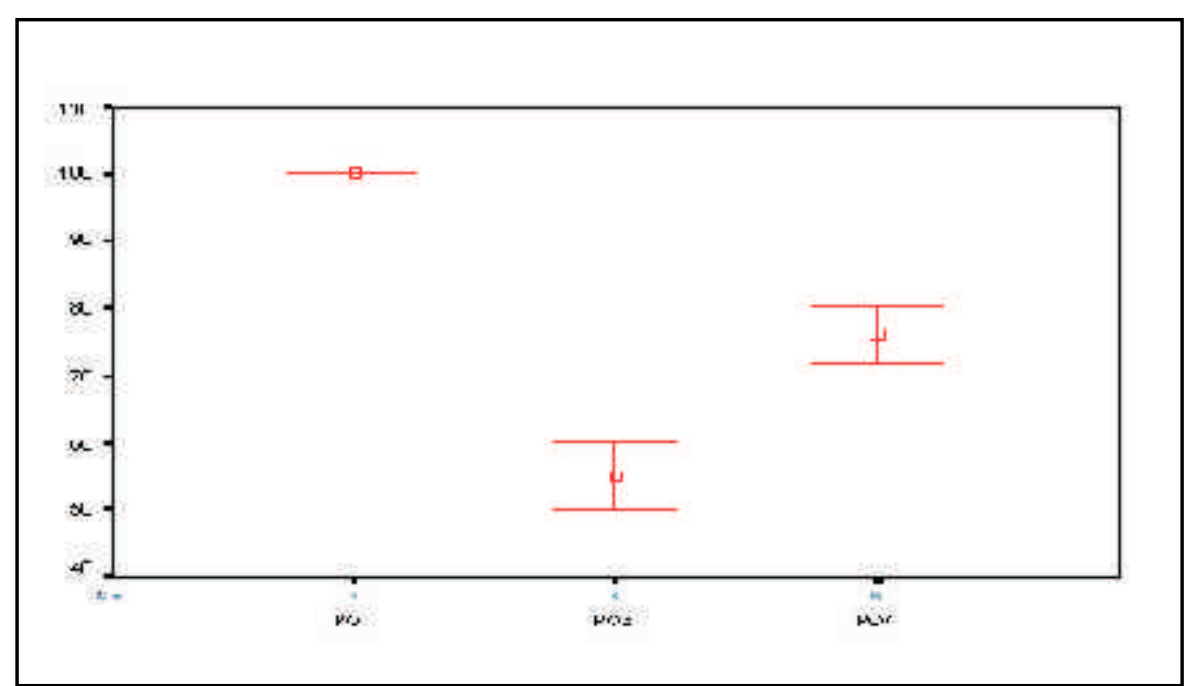

FIGURA 7 - Valor médio do PACN (\%) nos retalhos cutâneos dos animais, nos três grupos.

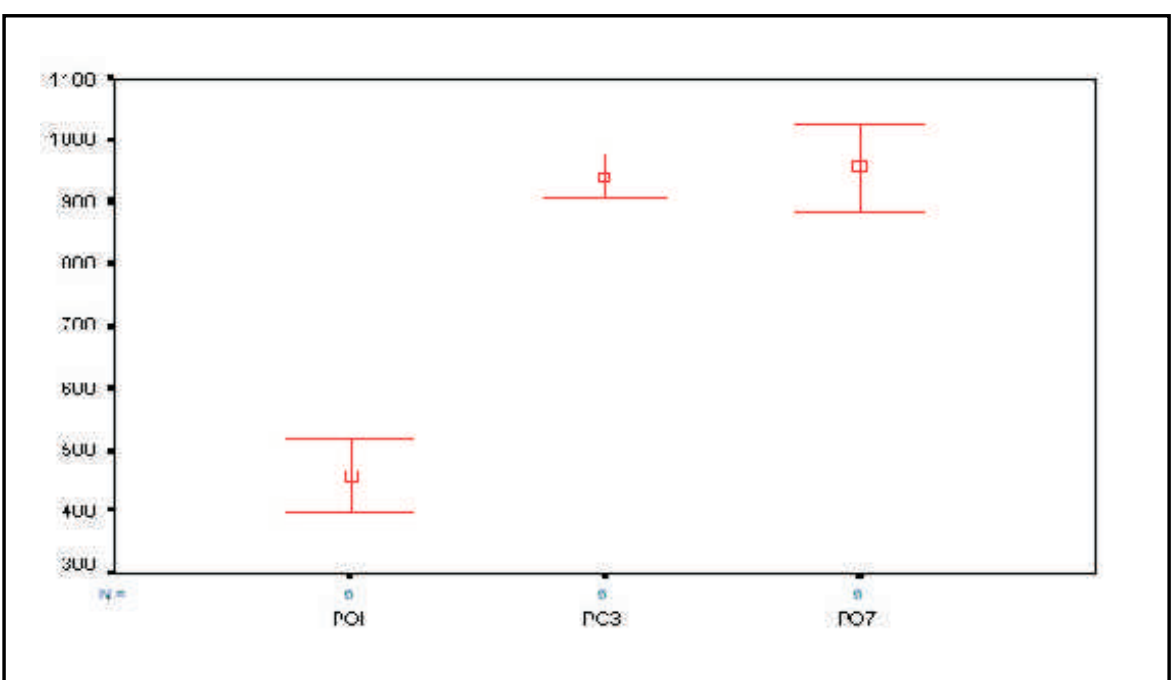

FIGURA 8 - Valor médio do MDA do soro (ng/ml) nos animais dos três grupos

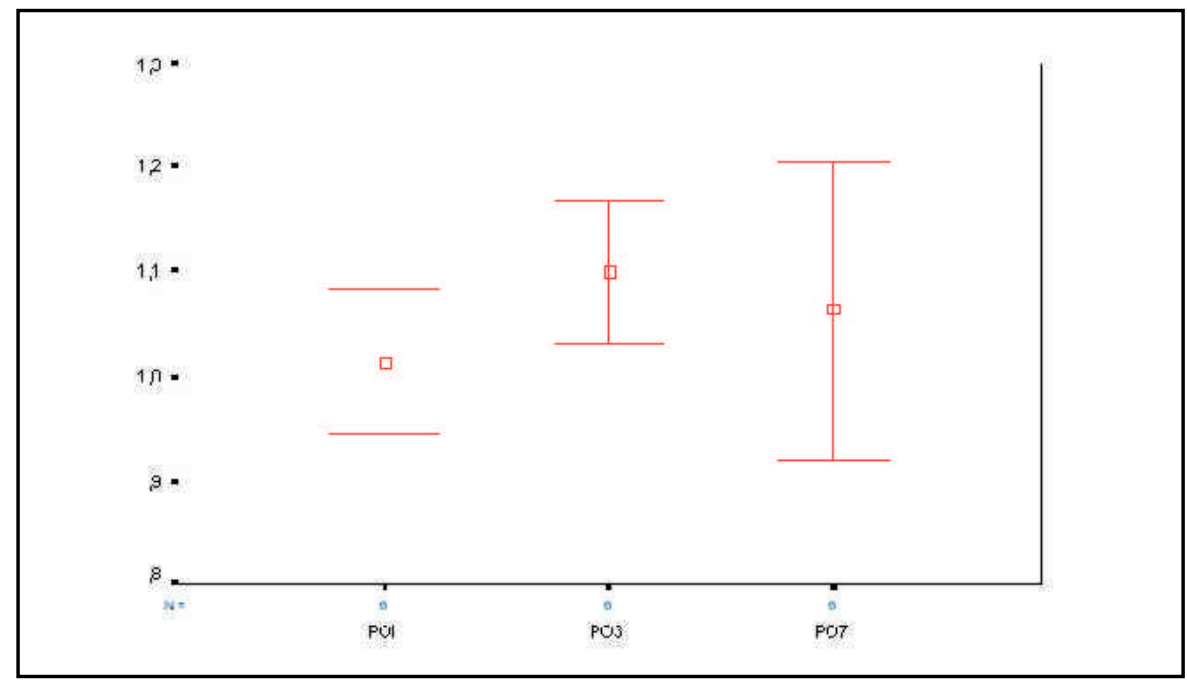

FIGURA 9 - Valores médios do MDA (ng/ml) nos fragmentos cutâneos nos animais dos três grupos 
Comportamento do estresse oxidativo e da capacidade antioxidante total em ratos submetidos a retalhos cutâneos isquêmicos

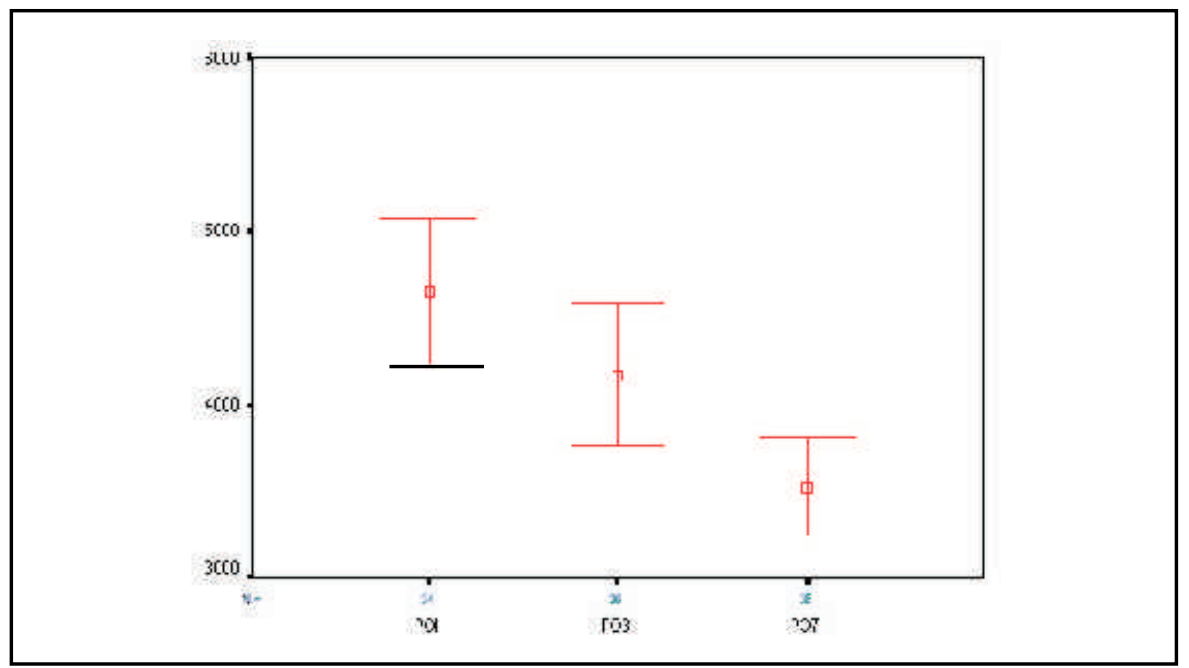

FIGURA 10 - Valores médios da CAT (ng/ml) no soro dos animais dos três grupos

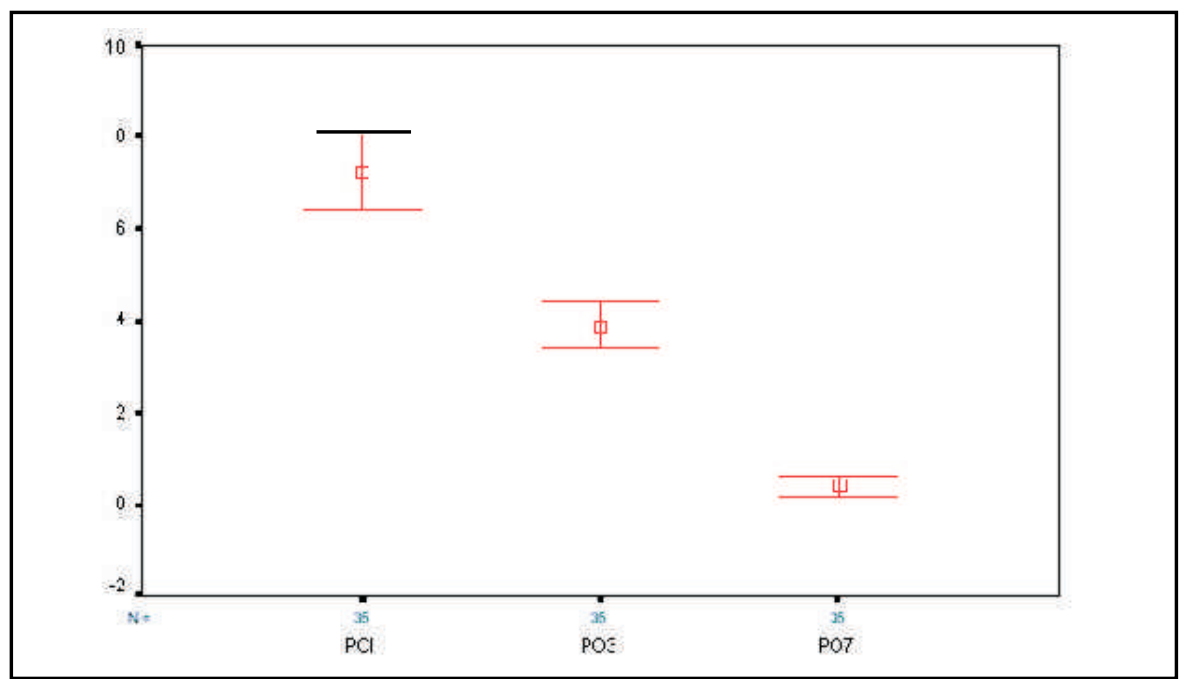

FIGURA 11 - Valores médios da CAT(ng/ml) nos fragmentos cutâneos dos animais dos três grupos

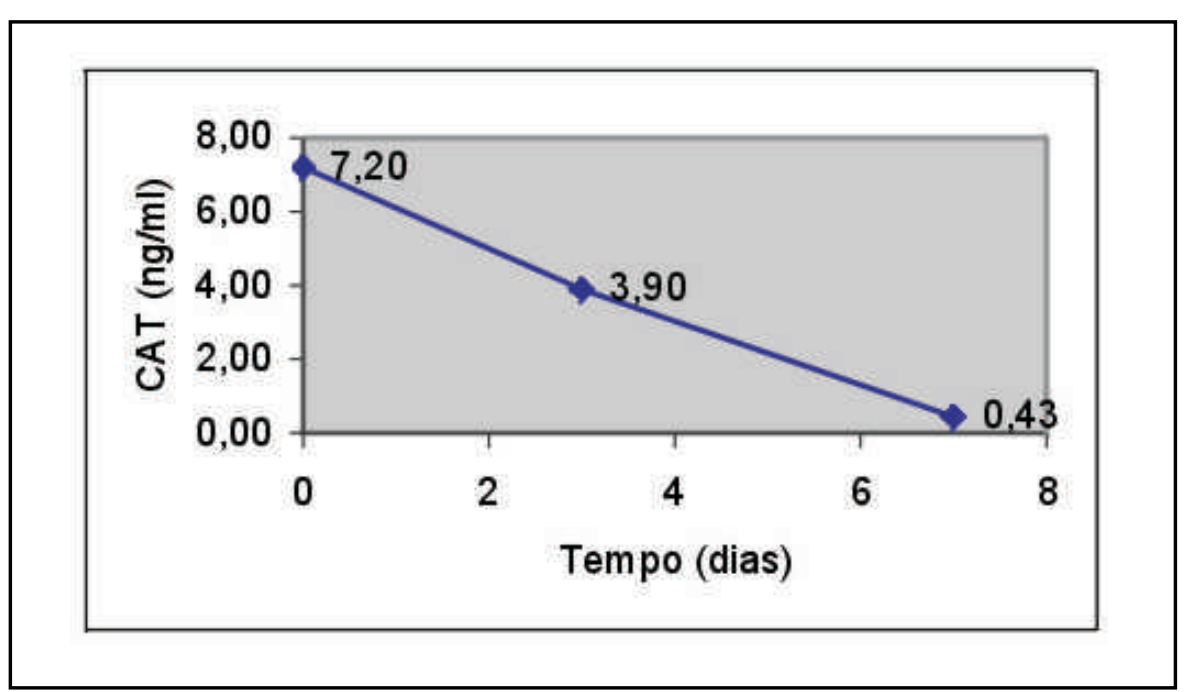

FIGURA 12 - Reta de regressão dos valores médios da CAT (ng/ml) ao longo do tempo (dias) 
TABELA 1 - Coeficiente de correlação entre os valores de MDA e CAT no soro dos animais dos três grupos

\begin{tabular}{cccc}
\hline Grupo & N & Coef.Corr. & P \\
\hline POI & 6 & $-0,658$ & 0,156 \\
PO3 & 6 & $-0,028$ & 0,958 \\
PO7 & 6 & $-0,045$ & 0,931 \\
\hline
\end{tabular}

TABELA 2 - Coeficiente de correlação entre os valores médios do MDA e CAT, nos fragmentos cutâneos nos grupos POI e PO3

\begin{tabular}{ccccccc}
\hline & \multicolumn{7}{c}{ GRUPO } \\
\cline { 2 - 6 } Posição & $\mathrm{n}$ & Coef. Corr. & $\mathrm{p}$ & $\mathrm{n}$ & Coef. Corr. & $\mathrm{p}$ \\
\cline { 2 - 6 } & 6 & $-0,237$ & 0,651 & 5 & $-0,070$ & 0,911 \\
1 & 6 & 0,191 & 0,717 & 6 & $-0,622$ & 0,187 \\
3 & 5 & $-0,730$ & 0,162 & 6 & $-0,473$ & 0,343 \\
4 & 6 & $-0,017$ & 0,974 & 6 & $-0,064$ & 0,904 \\
5 & 5 & $-0,354$ & 0,559 & 6 & $-0,415$ & 0,413 \\
Controle & 6 & 0,407 & 0,423 & 6 & $-0,200$ & 0,704 \\
\hline
\end{tabular}

Em todos os cálculos encontramos $\mathrm{p}$ de $5 \%$, não existe relação linear entre as superior a 0,05 . No nível de significância variáveis MDA e CAT para os fragmentos.

TABELA 3 - Coeficiente de correlação entre os valores médios da PACN e MDA nos fragmentos cutâneos

\begin{tabular}{cccc}
\hline Grupo & $\mathrm{n}$ & Coef.Corr. & $\mathrm{P}$ \\
\hline PO3 & 6 & 0,357 & 0,487 \\
PO7 & 6 & $-0,315$ & 0,606 \\
\hline
\end{tabular}

TABELA 4 - Coeficiente de correlação entre os valores médios da PACN (\%) e da CAT médios (ng/ $\mathrm{ml})$, nos retalhos do grupo $\mathrm{PO} 3$

\begin{tabular}{cccc}
\hline Grupo & $\mathrm{n}$ & Coef.Corr. & $\mathrm{P}$ \\
\hline PO3 & 6 & $-0,130$ & 0,834 \\
\hline
\end{tabular}

Encontrou-se a seguinte reta de regressão: $\mathrm{CAT}=7,05$ - $0,96 \times$ tempo.

\section{Discussão}

Resolveu-se analisar o comportamento do estresse oxidativo, ou seja, a agressão tecidual causada pela presença de espécies reativas tóxicas do oxigênio e a defesa antioxidante total, em retalhos cutâneos randômicos isquêmicos do dorso de ratos, assim como a correlação entre estes parâmetros, em fragmentos pertencentes ao retalho, em amostras cutâneas não pertencentes ao retalho e no soro. A repercussão sistêmica desta agressão poderia trazer subsídio laboratorial para a prevenção medicamentosa precoce em isquemia pós-cirúrgica em Cirurgia Plástica. Não há na literatura trabalhos com estes parâmetros.

Embora a cútis do rato não tenha as mesmas características da humana, parte dos trabalhos destinados ao estudo da isquemia e da circulação cutânea tem se servido deste animal. A diferença entre ambas reside principalmente nas características do tecido subjacente à derme. No rato a camada muscular, ou panniculus carno$s u s$, é aderida a cútis e frouxamente a fáscia profunda, pelo tecido areolar frouxo, enquanto que, no ser humano, a gordura superficial ou panniculus adiposus é mais firmemente aderida a fáscia profunda. Em relação à irrigação cutânea, essas camadas são comparáveis, pela grande quantidade de vasos presentes ${ }^{8}$. Desta forma, se padronizou, utilizando aquele animal de experimentação, um retalho cutâneo dorsal com base proximal, desde o ângulo inferior das escápulas até a pelve, que resultaria em uma área isquêmica na sua extremidade. Sua dimensão é de, aproximadamente, 10 x $4 \mathrm{~cm}$ e envolveria sempre os mesmos vasos, sem uma nutrição axial.

Um estado hiperadrenérgico ocorre inicialmente, após secção de nervos simpáticos, por acúmulo de noradrenalina. A vasoconstrição resultante induz a oclusão capilar temporária, mas completa. Estas condições são compatíveis com a já bem descrita síndrome de isquemia e reperfusão, na qual são gerados radicais livres.

Embora diversos autores tenham investigado o uso de antioxidantes em tecidos isquêmicos com o objetivo de diminuir a necrose, não houve estudo acerca das defesas antioxidantes fisiológicas nestes modelos, de forma que este foi o objetivo central deste trabalho.

Ao longo de um retalho isquêmico existe uma área em que a sobrevida cutânea é esperada (porção proximal), pois o aporte de oxigênio é adequado ao metabolismo celular. Em outra (porção distal), a necrose é mais provável, pela incapacidade de manutenção metabólica necessária. Entre essas duas, há uma área, chamada de "zona de transição", submetida a um período de isquemia, seguido por gradual reperfusão ${ }^{10}$, onde uma adequada manipulação farmacológica tentaria diminuir a possibilidade de necrose ${ }^{11,12}$. No retalho cutâneo randômico isquêmico do dorso de rato, a secção de vasos perfurantes musculocutâneos permite apenas a irrigação através de plexo dermo-subdérmico, por ramos da artéria torácica superior. Para garantir tal exclusividade, utilizamos uma barreira plástica impermeável entre o retalho e seu leito, como preconizado por Ugland ${ }^{9} \mathrm{e}$ Kaufman e col. ${ }^{13}$, que impede a revascularização pelo seu leito.

Escolheu-se fragmentos alternados, desde a extremidade distal do retalho até sua base cranial, e outro fora do retalho, para 
analisarmos o estresse oxidativo e a defesa antioxidante em distâncias progressivamente menores da base do retalho, sendo a amostra do tecido de fora do retalho considerada como controle (não isquêmica). Coletou-se também amostras de soro, para estudar a repercussão sistêmica da isquemia/reperfusão.

A PACN média do grupo POI foi de $100 \%$, a do $\mathrm{PO} 3$ foi de $55.15 \%$ e do grupo PO7 de $76.33 \%$ (Figura 7). Todos os animais do grupo $\mathrm{PO} 7$ tiveram necrose da extremidade distal de seus retalhos, em concordância com os trabalhos que usaram retalhos semelhantes e barreira plástica sobre seu leito ${ }^{9,13,14}$.

As áreas de sofrimento cutâneo nos retalhos dos animais no terceiro dia pósoperatório podem evoluir, em parte para necrose e em parte para regeneração, o que explicaria a PACN média menor no grupo PO3 do que no PO7. Esta hipótese torna mais interessante o conhecimento do comportamento da agressão oxidativa e da defesa antioxidante nos fragmentos intermediários dos retalhos, ou seja, entre as extremidades (amostras 2 e 3), pois correspondem à transição da área cutânea normal para alterada (com sofrimento ou necrose).

Nesta pesquisa, os valores de MDA encontrados no soro dos animais aumentaram com o tempo, sendo significativamente menor a média no grupo POI (459.67 $\mathrm{ng} / \mathrm{ml}$ ) do que nos grupos PO3 (940.33 ng/ $\mathrm{ml})$ e no PO7 (956.67 ng/ml), que não diferiram entre si (Figura 8), sugerindo que as alterações oxidativas sistêmicas, neste modelo experimental, tenham início muito precoce, atingindo valores altos que se mantêm até o final do período estudado.

Em nosso trabalho, os valores médios de MDA nos fragmentos cutâneos não diferiram significativamente com o tempo (POI = PO3 = PO7), nem com a distância da base do retalho (Figura 9). Estes resultados aparentemente discordam dos obtidos no trabalho de que a concentração de peróxidos lipídicos aumentava significativamente nas primeiras 5 horas, retornando aos valores iniciais após a sexta hora ${ }^{6} \mathrm{e}$ em retalhos cutâneos de ratos, apontam o pico de elevação da peroxidação lipídica aos 10 minutos do período pós-operatório, retornado aos valores basais até o terceiro dia.

O grupo POI - o de menor intervalo de tempo entre a elevação do retalho e as coletas das amostras (tempo menor do que
1 minuto) - e o grupo PO3 - após 72 horas, não poderiam, portanto, evidenciar, no nosso trabalho, uma eventual elevação dos níveis de MDA. A inexistência de diferença entre os três grupos, no entanto, reforça a sugestão de Ashoori et al. ${ }^{6}$, de que os níveis de MDA retornam aos valores basais rapidamente.

Os valores médios da CAT no soro dos grupos POI (1.01 ng/ml), PO3 (1.10 ng/ml) e PO7 $(1.06 \mathrm{ng} / \mathrm{ml})$ não diferiram significativamente ao longo do tempo (Figura 10), provavelmente devido ao fato de que as alterações antioxidantes ocorridas no retalho não sejam suficientes para serem evidenciadas na circulação sistêmica, ou estas alterações ocorreriam precocemente, não podendo ser visualizadas neste modelo experimental.

No entanto, os valores médios da CAT nos fragmentos cutâneos mostraram-se significativamente maiores no grupo POI $(7.20 \mathrm{ng} / \mathrm{ml})$ do que no grupo PO3 (3.90 $\mathrm{ng} / \mathrm{ml})$ e estes maiores do que no grupo PO7, cujos valores não foram analisados estatisticamente pela grande quantidade de resultados "indetectável", expresso, numericamente por "zero" (Figura 11). Estes resultados sugerem um consumo local desta capacidade ao longo do tempo de exposição à isquemia e, conseqüentemente, ao estresse oxidativo.

Considerando-se que não houve diferença nos valores de MDA e da CAT entre os fragmentos cutâneos dos retalhos e as amostras de fora dos retalhos (Tabela 2) alguns fatores devem ser levados em conta para explicar o porquê da necrose dos fragmentos do grupo $\mathrm{PO} 7$ e não das amostras de controle.

Bhatnagar ${ }^{15}$ defende a idéia de que a peroxidação lipídica, por si só, não leva ao dano celular irreversível. Como a membrana plasmática tem sua estrutura básica formada por lipídios, a maior parte dos radicais livres gerados pela introdução de algum fator exógeno vai reagir primeiro com essa membrana, antes de se difundir ao interior da célula e iniciar a agressão em sítios mais críticos. Seu trabalho forneceu dados que sugerem que os danos irreversíveis causados pelos radicais livres se devam à oxidação dos tióis protéicos. $\mathrm{O}$ acúmulo de produtos da peroxidação lipídica ou a perda de energia celular não corresponderiam à perda da viabilidade celular.
Mas estas idéias não justificam a diferente evolução clínica dos fragmentos.

Supomos haver fatores imprescindíveis para a sobrevida das amostras de controle que, em nenhum dos animais, sofreram necrose. Estes fatores poderiam corresponder ao maior aporte de elementos sangüíneos de reparação e defesa celular, não avaliados pelo desenho deste trabalho.

O coeficiente de correlação negativo entre os valores de MDA e CAT no soro dos animais do grupo POI (Tabela 1), nos quais se encontraram os maiores valores da CAT, sugere que os níveis de MDA sejam mantidos em valores baixos às custas da defesa antioxidante elevada durante o primeiro minuto após elevação do retalho.

Paralelamente, Ashoori e col. ${ }^{6}$, mostraram que o MDA tem seu pico, nas amostras cutâneas, aos 10 minutos após a elevação do retalho, quando ocorre um provável consumo das defesas antioxidantes endógenas, sem que haja condições do organismo produzir um aumento nas defesas sintetizáveis (tais como enzimas antioxidantes e glutationa reduzida).

A correlação negativa dos valores de MDA e CAT dos fragmentos cutâneos encontrada em todas as posições dos animais do grupo PO3, (tabela 2) (valores de CAT diminuem em relação aos do MDA), sugere o consumo local de antioxidantes, exatamente em posições intermediárias do retalho isquêmico, onde a agressão oxidativa não obrigatoriamente se reverte em dano tecidual. A defesa antioxidante total (que se consome), somada à capacidade regenerativa das células, parece conseguir deter esta agressão, o que justificaria o achado que obtivemos em relação a PACN, em que o grupo PO7 apresentou médias significativamente maiores $(84.1 \%)$ do que o grupo PO3 (68.7\%).

Nos animais dos grupos PO3 e PO7 houve maior tempo de exposição dos fragmentos cutâneos aos mecanismos oxidativos (3 e 7 dias, respectivamente), porém, não acompanhado por aumento dos valores de MDA, quando comparados ao grupo POI. A manutenção destes valores pode significar a inexistência de aumento de agressão, apesar de maior tempo de exposição à síndrome de isquemia/reperfusão, ou retorno aos valores basais, em concordância com os achados de Ashoori e col. ${ }^{6}$, que mostram o declínio destes valores até o terceiro dia após elevação do retalho e, portanto, anteriores ao PO3. 
O achado de diminuição dos valores da CAT nos fragmentos cutâneos, entre os grupos $\mathrm{PO} 3$ e $\mathrm{PO} 7$ demonstra que, embora não haja aumento dos valores de MDA, há um evidente consumo das defesas antioxidantes, demonstrando efetiva participação do fenômeno de estresse oxidativo, o qual culmina com o estabelecimento de necrose, observada nos animais do grupo PO7.

Estes resultados, senão totalmente reveladores, são indicadores de caminhos e nos abrem um amplo horizonte. $\mathrm{O}$ trabalho não se encerra aqui, muito pelo contrário, desperta o interesse para novas pesquisas, principalmente para: a) um melhor entendimento do comportamento das vias antioxidantes envolvidas neste modelo; b) maior caracterização das alterações oxidativas/ antioxidantes, nos primeiros minutos, após a elevação do retalho; c) o potencial uso de substâncias antioxidantes na prevenção da necrose; d) extrapolação dos resultados encontrados nessa etapa, para os eventos cirúrgicos, em humanos.

\section{Conclusões}

O estresse oxidativo sistêmico, avaliado pela dosagem de MDA no soro dos animais, aumentou entre o grupo POI e o grupo PO3, mantendo-se elevado no grupo PO7. No entanto, o estresse oxidativo local, avaliado pela dosagem de MDA nos fragmentos cutâneos, não apresentou diferença significante entre os três grupos.

A defesa antioxidante total sistêmica, avaliada pela dosagem da CAT no soro dos animais, não diferiu entre os grupos estudados. No entanto, a CAT local, avaliada pela dosagem da CAT nos fragmentos cutâneos, diminuiu com o tempo de exposição ao estresse oxidativo.

A inexistência de diferença para os valores de MDA nas amostras cutâneas entre os grupos e a diminuição dos valores da CAT ao longo do tempo sugerem que a presença de necrose na porção distal dos retalhos dos animais do grupo $\mathrm{PO} 7$ decorra, não somente da agressão oxidativa, mas principalmente, da diminuição da capacidade de defesa antioxidante local.

\section{Referências}

1. Hayden RE, Paniello RC, Yeung CST, Bello SL, Dawson SM. The effect of glutathione and vitamins $\mathrm{A}, \mathrm{C}$ and $\mathrm{E}$ on acute skin flap survival. Laringoscope 1987; 97:1176-9.

2. Willms-Kretschmer K, Majno G. Ischemia of the skin. Am J Pathol 1969; 54:327-43

3. McCord JM. Oxygen derived radicals: a link between reperfusion injury and inflammation. Fed Proc 1987; 46:2402-6.

4. Cino M, Del Maestro RF. Generation of hydrogen peroxide by brain mitochondria: the effect of reoxygenation following postdecapitative ischemia. Arch Biochem Biophys 1989; 269: 623-38.

5 - Manson PN, Narayan KK, Im MJ, Bulkley GB. Hoopes JE. Improved survival in free skin flap transfers in rats. Surgery 1986; 99:211-5.

6 - Ashoori F, Suzuki S, Zhou JH, Isshiki N, Miyachi Y. Involvement of lipid peroxidation in necrosis of skin flaps and its suppression by ellagic acid. Plast Reconst Surg 1994; 94:1027-37.
7. Adamson JE, Horton CE, Crawford HH, Ayers WT. Studies on the action of dimethyl sulfoxide on the experimental pedicle flap. Plas Reconst Surg 1967; 39:142-6.

8. McFarlane RM, De Young G, Henry RA. The design of a pedicle flap in the rat to study necrosis and its prevention. Plast Reconstr Surg 1965; 35:177-82.

9. Ugland O. Dicoumarol administration to rats with skin flaps. Acta Chir Scand 1966; 131:408-12.

10. Sasaki GH, Pang CY. Hemodynamics and viability of acute neurovascular island skin flap in rats. Plast Reconstr Surg 1980; 65:152-8.

11. Costa Neto PLO. Estatística matemática I. 2ed. São Paulo: Edgard Blücher; 1978.

12 . Paniello RC, Hayden RE, Bello SL. Improved survival of acute skin flaps with amino acids as free radical scavengers. Arch Otolaryngol Head Neck Surg 1988; 4:1400-3.

13. Kaufman T, Angel MF, Eichenlaub EH, Levin M, Hurwitz DJ, Futrell JW. The salutary effects of the bed on the survival of experimental flaps. Ann Plastic Surg 1985; 14: 64-73.

14. Gomes HFC, Bueno PCS, Scardoeli CAA, Landman MRL, Ishizuka MMA, Martins DMFS, Andrews J M. Effect of nicotine in randomized skin flaps in rats. Rev Hosp São Paulo Esc Paul Med 1994; 5:13-7.

15. Bhatnagar A. Biochemical mechanism of irreversible cell injury caused by free radicalinitiated reactions. Mol Cell Biochem 1994; 137:9-16.

\section{Agradecimentos}

Os autores são gratos ao Prof. Ms. Élio Fernandes Más e a Profa. Maria Isabel Hernandez Más pelas sugestões e pelo auxílio na revisão do manuscrito.

\begin{abstract}
Cymrot M, Percário S, Ferreira LM. Oxidative stress and total antioxidant status in ischemic skin flaps in rats. Acta Cir Bras [serial online] 2004 Jan-Feb;19(1). Available from URL: http://www.scielo.br/acb

ABSTRACT - Purpose: to study oxidative stress (MDA) and total antioxidant status (CAT) in fragments of randomic ischemic skin flaps from rat dorsum. Methods: 18 male rats, young adults (Wistar EPM-1, 290 - 350g), that underwent elevation of randomic ischemic flaps from dorsum, were divided in three groups $(\mathrm{N}=6)$, according to post-operative time-points: immediate (POI), third and seventh post-operative days (PO3 and PO7), respectively. At the end, peripheral blood samples and tissue fragments of the flap and of normal skin outside flap were draw for MDA and CAT measurement. Results: serum MDA values in group POI were significantly lower than those in PO3 and PO7, both latter in the same range. No differences were found among MDA values of the skin samples in any of the three groups. The analysis of the total antioxidant status of the animal's serum (CAT) did not show significant differences among the three groups. However, in the skin flap samples, the CAT values significantly decreased with time. Conclusion: The lack of significant differences among MDA values in skin samples from all groups, and the decreasing CAT values with time, suggest that the existence of necrosis at the distal portion of flaps in group PO7 is due not only to oxidant aggression but mainly to the reduction of local antioxidant status.
\end{abstract}

KEY WORDS - Skin flaps. Free radicals. Antioxidants. Rats.

Correspondência:

Lydia Masako Ferreira

Rua Botucatu, 591/143

4023-62 São Paulo - SP
Conflito de interesse: nenhum Fonte de financiamento: nenhuma

Data do recebimento: $25 / 10 / 2003$

Data da revisão: $11 / 11 / 2003$

Data da aprovação: 28/11/2003

Fotos coloridas disponíveis em www.scielo.br/acb <http://www.scielo.br/acb $>$ 